\title{
COMUNICAÇÃO NÃO VIOLENTA: A VISÃO DO ALUNO EM PROJETO DESENVOLVIDO NO AMBIENTE ESCOLAR
}

\section{ARTIGO ORIGINAL}

LIMA, Marcos Antônio de ${ }^{1}$

NASCIMENTO, Luiz Hermínio do ${ }^{2}$

LIMA, Marcos Antônio de. NASCIMENTO, Luiz Hermínio do. Comunicação Não Violenta: a visão do aluno em projeto desenvolvido no ambiente escolar. Revista Científica Multidisciplinar Núcleo do Conhecimento. Ano 04, Ed. 11, Vol. 03, pp. 21 35. Novembro de 2019. ISSN: 2448-0959, Link de acesso: https://www.nucleodoconhecimento.com.br/educacao/projeto-desenvolvido

\section{RESUMO}

Trabalhar no ambiente escolar a importância de uma relação social saudável torna-se um papel fundamental. A empatia deve se um dos ser um ponto comum na instituição, gerando assim, harmonia entre os envolvidos no processo de ensino aprendizagem. Com este olhar a necessidade de uma escola Estadual de um interior de RN ampliou seu trabalho focado na Comunicação não violenta, ao observar que em seu ambiente os alunos estavam agredindo-se com excessividade. Com todo o trabalho

1 Mestrando Multidisciplinar Profissional em Ciências da Educação/CECAP Pósgraduado em Ensino e Aprendizagem de Línguas/UFRN, - Graduado em Letras/UFRN.

2 Doutorado em andamento em Ciências da Educação. Mestrado em Mestrado em Ciências da Educação. Especialização em Curso de Pós -Graduação em Educação, Desenvolvimento. Especialização em Gestão de Qualidade e Produtividade. Especialização em Especialização em Administração Escolar. Especialização em Especialização em Supervisão Escolar. Graduação em Licenciatura Plena em Pedagogia. 
desenvolvido chegou a hora de analisar o pós projeto, desta forma, o artigo tem como objetivo analisar o reflexo do projeto sobre a Comunicação Não Violenta- CNV desenvolvida na escola E.M.A.P, interior do RN na visão do aluno. Trata-se, portanto, de uma pesquisa de campo, com instrumento de pesquisa utilizada através de questionários visando a análise de forma qualitativa e quantitativa seus dados obtidos. Seu desenvolvimento tem importância na compreensão que o projeto como meio transformador da relação entre dos alunos surtiu efetividade.

Palavras-chaves: CNV, relação social, empatia.

\section{INTRODUÇÃO}

A comunicação não violenta tem se destacado em todos os ambientes sociais na busca de uma melhor interação social entre os indivíduos, de modo que tudo possa ser solucionado através de diálogos e ações que permitam uma relação mais saudável, posicionando-se na transparência e positivamente como se sente em relação a ação do outro. O psicólogo Marshall Rosenberg foi o profissional que desenvolveu a linha de pesquisa sobre a importância do diálogo com base para a relação entre os indivíduos.

Tendo como norte a empatia ao próximo, ou seja, a necessidade de potencializar a relação interpessoal das pessoas, buscando-se a sensibilidade para com o outro centrada na atenção da pergunta e resposta, ou seja, utilizando-se principalmente os pilares envolvidos como Observação, Sentimento, Necessidade e Pedido, como meio de sensibilizar o aluno a ver o outro com olhar mais amplo e colocando-se no lugar do mesmo para compreender sua posição, visão e entendimento.

Através da comunicação que se dá pelo diálogo, estabelece-se uma relação mútua. O importar-se, o colocar-se no lugar do outro, enriquece a si e oportuniza o próximo a abrir-se para o que Ihe inquieta. "Comunicar-se é nada menos que o ápice do fato da vida estabelecer-se como relação" (PELIZZOLI, 2012, p.2). Em seu livro, escrito em 2006, Rosenberg vem abordar a observação como a necessidade de olhar para o outro sem julgar, sem criar preceitos sobre o mesmo, desta maneira, será possível 
apenas centrar no que tem na pessoa que não nos agrada, filtrar este ponto e trabalhar a comunicação de forma mais positiva, de modo que o outro o ajude naquilo que pode deixar sua vida mais enriquecedora. "Julgamentos, críticas, diagnósticos e interpretações dos outros são todas expressões alienadas de nossas próprias necessidades e valores" (ROSENBERG, 2006, p. 95).

Portanto, é preciso transparecer a capacidade do outro sentir-se no lugar (em que lugar?) ou contribuir para melhorias esclarecendo o que se faz necessário e em seguida apresentar explicitamente um pedido (que pedido?) para o outro disponibilizar-se a cumprir, pelo fato da empatia trazer esta contribuição. Os pilares são os pontos fortes, para uma compreensão mais ampla a figura 1 explana:

Figura 1: Pilares da CNV

\section{Observacões}

O que podemos ouvir, observar: os fatos

\section{Sentimento}

Nossa reação emocional em relação a isto

\section{Necessidade \\ O que realmente é importante para nós, nosso valor}

\section{Pedido/estratégia \\ O que pode atender nossa necessidade}

Fonte: PDF Emdec

Pelizzoli (2012) tendo como base estes pilares pontuam atos que são fundamentais para esta prática de compreensão da Comunicação Não Violenta, do qual destaca a capacidade de enxergar o sujeito, o ser individual, suas buscas por construção de sua 
identidade, em equilibrar a diversidade da interdependência, sua responsabilidade e vulnerabilidade, na sua capacidade de poder melhorar no que é necessário em si, e poder ajudar o outro.

Em destaque ao segundo ato, o outro, a construção de sensibilizar com o outro, agindo sobre a ética, não em aceitar simplesmente as diferenças, ou querer mudar no outro aquilo que não Ihe agrada, está justamente na capacidade do indivíduo saber lidar com esta diferença no seu cotidiano.

A tarefa da CNV é ajudar a entender os conflitos negativos, atuar em suas causas (atuar até certo ponto, pois muitas questões ultrapassam sua esfera, como questões econômicas ou psicológicas mais graves), e promover as estratégias positivas, resolutivas e de relacionamentos saudáveis, por meio do encontro e da comunicação sem bloqueios (PELIZZOLI, 2012, p.8)

Os conflitos existentes em qualquer relação na visão de Pelizzoli, precisam partir da intersubjetividade, ou seja, partir de um diálogo que permita se ter uma compreensão das inquietações existentes no outro, do seu modo de pensar ou ver situações. "Dialogar é mais que mediar, é trazer à tona efeitos humanos e psicológicos dos malfeitos, é abrir-se ao outro, é tentar entender e ouvir de fato - não apenas para logo atacar" (PELIZZOLI, 2012, p.8).

Diante de um trabalho desenvolvido pela escola E.M.A.P no, interior do RN, onde teve como base a Comunicação Não Violenta, após a identificação que na escola os alunos estavam muitos violentos física e verbalmente uns com os outros, a equipe gestora, pedagógica e de professores desenvolveram um projeto de ação em que os alunos pudessem praticar a linha de Comunicação não violenta-CNV.

Partindo do conhecimento que o projeto realizado teve seu momento ápice, o artigo tem em sua problemática saber: O projeto Comunicação Não Violenta" desenvolvida pela Escola E.M.A.P no interior do RN, influenciou na mudança da relação e na comunicação entre os alunos efetivamente? 
$\mathrm{O}$ artigo desenvolve-se justamente como anseio de analisar os reflexos pós projeto desenvolvido na escola E.M.A.P com a Comunicação Não Violenta, visando também identificar as mudanças ocorridas no âmbito escolar e para a vida na visão do aluno.

Justifica-se pela importância da possibilidade desta prática ser evidenciada como meio transformador da relação dos alunos entre si, principalmente como o conhecimento de si mesmo e da sua expressão clara como indivíduo participante de uma relação, considerando que os mesmos em fase de adolescência, além de seus conflitos internos, estão muitas vezes em ambientes diferenciados de crenças, cultura, de estrutura familiar e de educação que por vezes os desnorteiam mais que os orientam.

\section{MATERIAIS E MÉTODOS}

A pesquisa tem sua definição como uma pesquisa de campo, do qual busca-se na sua objetividade encontrar os resultados refletidos do projeto desenvolvido pela escola com os alunos de 6ำ ao 9 de uma escola pública na cidade de Currais Novos/RN. Por solicitação da gestora a mesma não terá sua identificação revelada denominada como Escola E.M.A.P., no interior do RN. A escola atua com 10 turmas que totalizam 628 alunos matriculados em atendimento de dois turnos.

Quanto a sua natureza é uma pesquisa aplicada, do qual visa solução de sua problemática, com relação aos seus objetivos a mesma define-se como descritiva, pois, "visa a descrever as características de determinada população ou fenômeno ou o estabelecimento de relações entre variáveis. Envolve o uso de técnicas padronizadas de coleta de dados" (PRODANOV e FREIAS, 2013, p.52).

Quanto aos procedimentos técnicos, pode-se destacar que para obtenção de dados aplicou-se um questionário aos alunos do $6^{\circ}$ ao 9o da Escola E.M.A.P. onde a participação destes alunos deu-se de modo voluntário, tendo uma participação de 120 alunos. Em um semestre anterior a escola havia desenvolvido o Projeto Comunicação Não Violenta, por perceber como a relação entre os alunos estava desarmoniosa, alunos muito agressivos, falavam alto, com desrespeito para com o outro, insultos e 
muitas vezes destruindo o ambiente educacional, muitos alunos estavam isolando-se por não conseguirem impor-se diante de determinadas situações.

Frente a esta realidade os gestores junto aos professores e funcionários desenvolveram o projeto que gerou a ação de diversas atividades que interagissem com os alunos e os motivassem a mudar. A gestora diz que "o diálogo foi o ponto de partida para iniciar o projeto". Isto porque foi através deste diálogo entre educadores, funcionários e gestores que possíveis ações deram passos para abordagem mais dinâmica com os alunos oportunizando os mesmos a falarem e agirem com mais efetividade diante dos problemas que estava ocorrendo no externo, a falta da comunicação não violenta define-se como:

[..] um processo de entendimento que facilita a harmonização de suas necessidades com as necessidades de outras pessoas, de uma maneira empática. Ele envolve, inicialmente, uma mudança de foco - de nossos erros e dos erros do outro às necessidades de todos (FRANKE, OLIVEIRA, MARINI, 2013, p. 2).

Para os educadores este projeto seria um norte para que o aluno externasse seus sentimentos e situações existentes para que a escola em união minimizasse ou eliminasse a violência existente no ambiente, com a contribuição de cada um. Foram realizadas oficinas, grupos de diálogos, de apoio, ações e atendimento com profissionais, como psicólogo. Após um semestre em que o trabalho foi realizado na visão dos educadores, gestores e funcionários houve uma melhoria na relação entre os alunos, contudo, eis o momento de conhecer estas mudanças na visão dos alunos.

\subsection{PONTOS DE DISCUSSÕES DOS RESULTADOS OBTIDOS: VISÃO DOS ALUNOS PÓS PROJETO CNV}

Dos alunos participantes da pesquisa $80 \%$ são do sexo feminino que se dispuseram a responder a pesquisa através de preenchimento dos questionários aplicados, enquanto $20 \%$ são masculinos. Dos alunos participantes o percentual por turma foi variável, tendo o 6ํㅗ Ano a maior participação. 
Gráfico 1: Percentual de alunos participante por turma

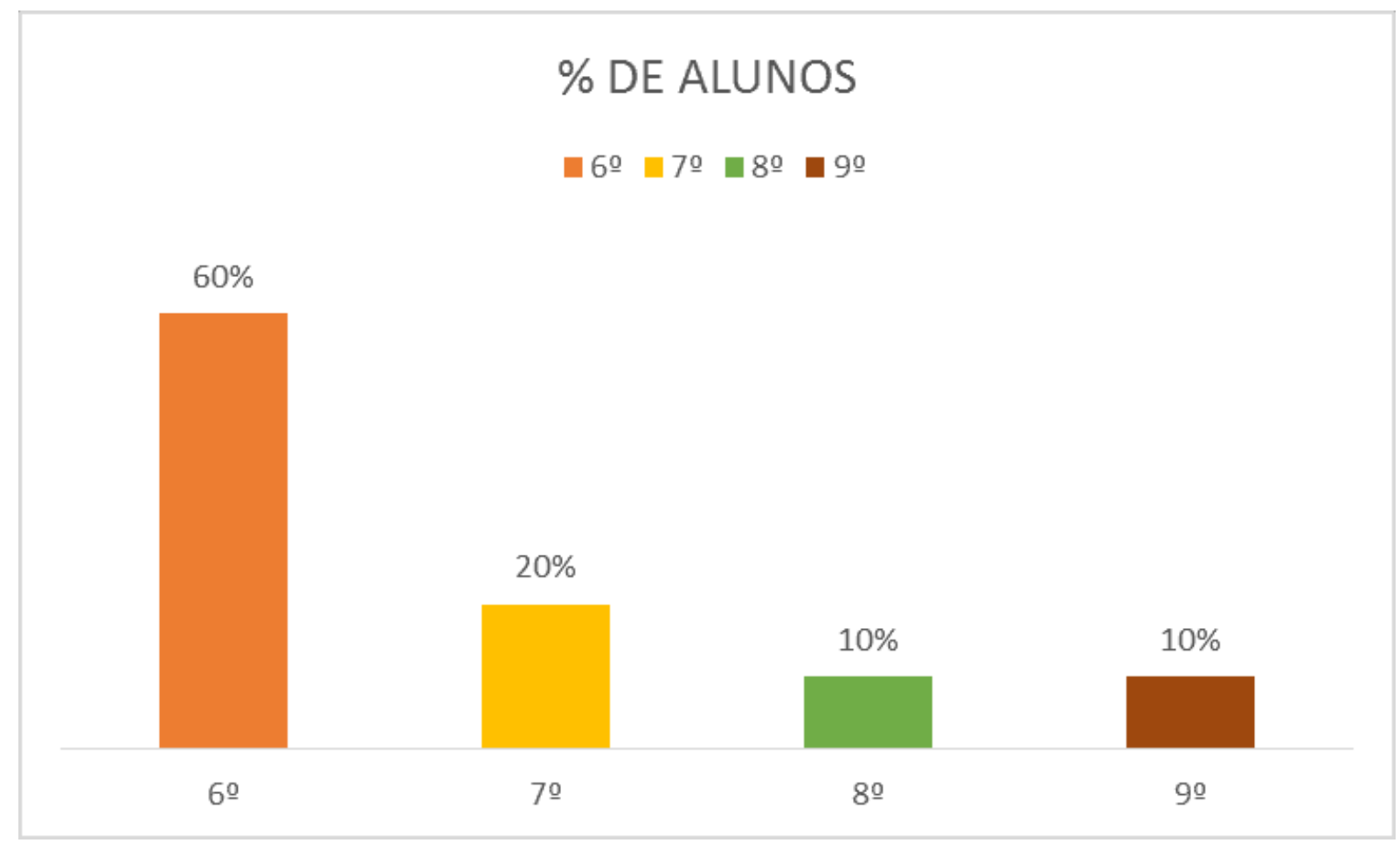

Fonte: Obtidas na pesquisa, 2019.

A disponibilidade dos alunos e interação na pesquisa foi de suma importância para que os dados obtidos apresentassem os resultados significativos. Mesmo o pesquisador tendo interesse de ter um número maior, respeitou o direito de quem não quis contribuir.

Destes alunos participantes $40 \%$ estudam a menos de um ano, $30 \%$ estudam a um ano na escola, $20 \%$ estudam a três anos e $10 \%$ a quatro anos. Vale ressaltar que alguns destes alunos não estudam desde o $6^{\circ}$ na escola ou ainda são alunos que se evadiram em um certo período.

Ao destacar sobre o projeto realizado pela escola, questionando aos alunos o conceito formado por eles após a vivência deste sobre a Comunicação Não Violenta, ao solicitar dois exemplos principais para definição sobre CNV, 60\% dos alunos destacaram em seu maior significado como: "momento para dialogar", ficando "compreender e ouvir o outro com $30 \%$. 
Gráfico 2: Conceito sobre Comunicação Não Violenta

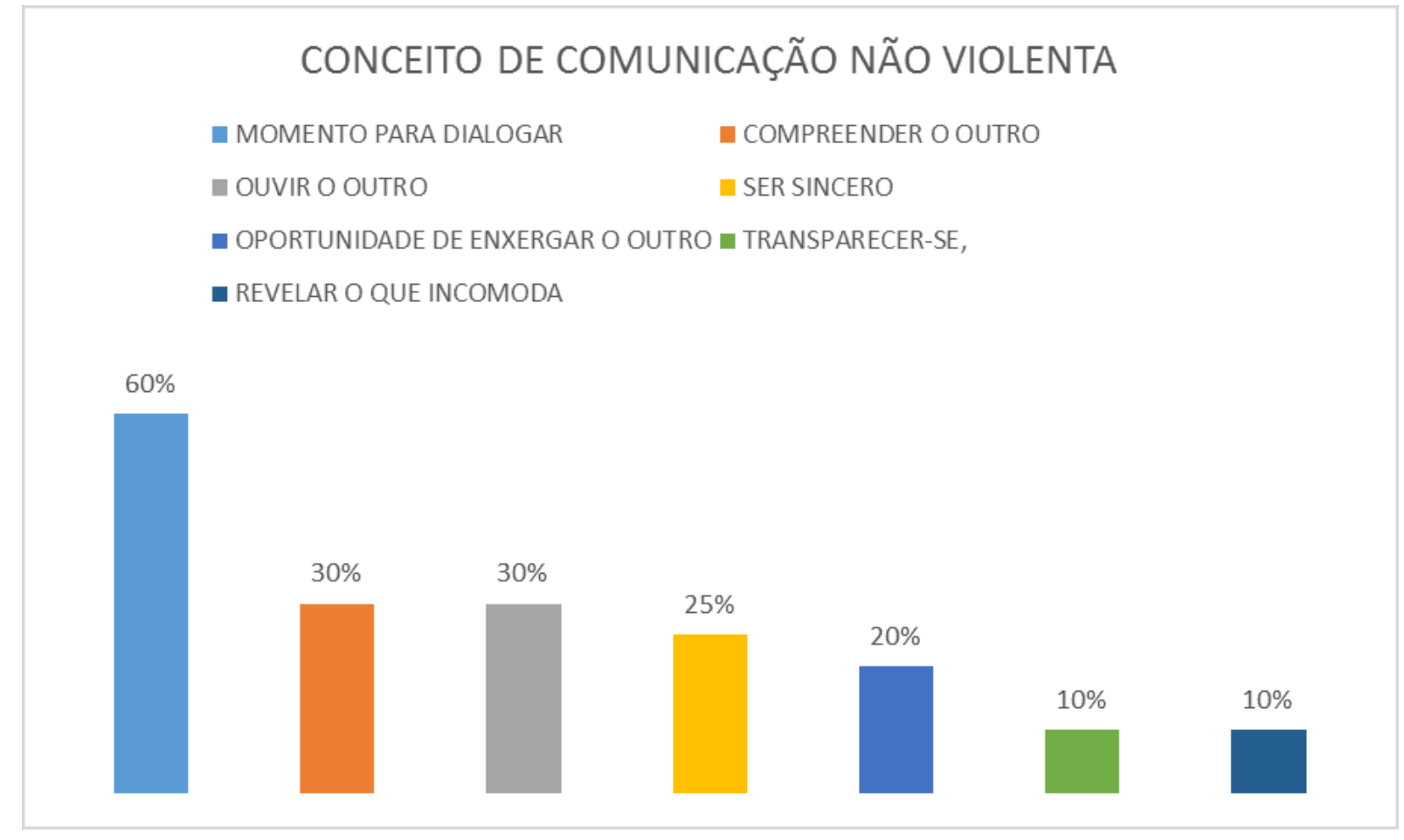

Fonte: Obtidas na pesquisa, 2019.

Ao analisar as conceituações dos alunos, verifica-se que os mesmos em seu contexto maior, compreenderam o conceito da temática trabalhada, pois a Comunicação Não Verbal define-se em seu desenvolvimento justamente a capacidade e habilidade que o indivíduo exercita em ouvir o outro, dialogar, expondo suas posições, como se sente, modo de pensar, mas, ao mesmo tempo em oportunizar ao outro a mesma abertura. Conforme explica Franke, Oliveira e Marini (2013, p. 4) "a Comunicação Não Violenta é um processo de entendimento que facilita a harmonização de suas necessidades com as necessidades de outras pessoas, de uma maneira empática".

Contudo, se faz importante explicar que Rosenberg define como empatia, para o autor "empatia é a compreensão respeitosa do que os outros estão vivenciando. Em vez de oferecermos empatia, muitas vezes sentimos uma forte urgência de dar conselhos ou encorajamento e de explicar nossa própria posição ou nossos sentimentos" (ROSENBERG, 2006, p. 150) 
Foi questionado aos alunos se antes do projeto ser trabalhado havia atos de violência presente na escola, solicitando exemplos. $65 \%$ dos alunos disseram que havia, e acrescentando que já havia presenciado. Dos exemplos citados A violência verbal foi a mais presenciada, com um percentual de $40 \%$, seguida da violência física e verbal com $35 \%$.

Gráfico 3: Tipos de violência presenciados na escola

\section{TIPOS DE VIOLÊNCIA PRESENCIADOS NA ESCOLA}

-VIOLÊNCIA FÍSICA $\quad$ VIOLÊNCIA VERBAL $\quad$ VIOLÊNCIA VERBAL E FísICA

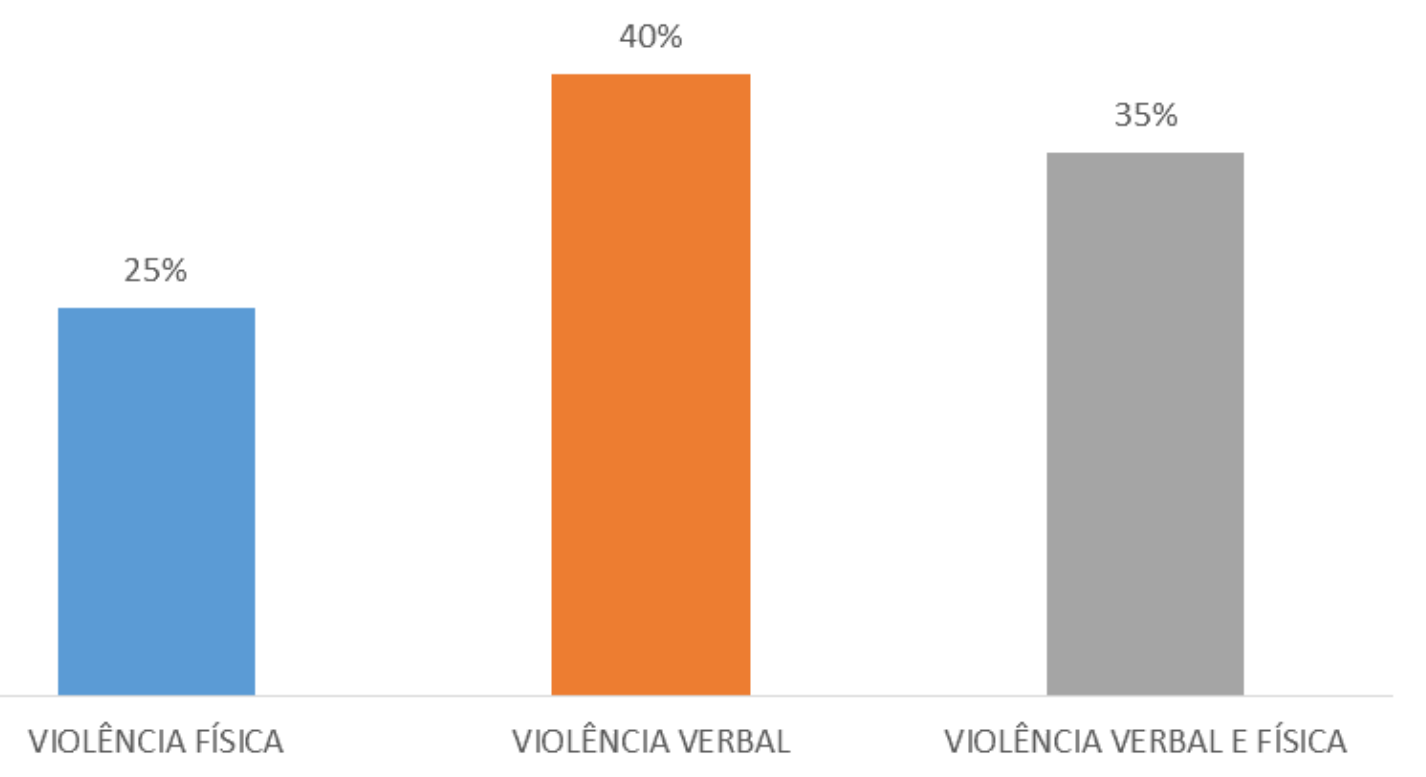

Fonte: Obtidas na pesquisa, 2019.

Os adolescentes costumam expressar suas insatisfações para com os outros, eles se insultam verbalmente, "para aparecer", para humilhar o outro, estes atos são constituídos geralmente por ações que denigrem o outro moral ou fisicamente, afetando consideravelmente o psicológico do indivíduo sofrido. Definido esta situação como bullying, sendo o reflexo da ausência da Comunicação Não Violenta, nas escolas públicas, bem como particular (mas, ágil em resolver conflitos), tem sido muito comum ver ações que se caracterizam com este conceito. Sobre este Tositto destaca como: 
Bullying é uma situação que se caracteriza por agressões intencionais, verbais, virtuais ou físicas, feitas de maneira repetitiva, por um ou mais alunos contra um ou mais colegas. Pode ocorrer em qualquer contexto social, como escolas, universidades, famílias, vizinhança e locais de trabalho $(2016$, p. 2).

Neste, se faz preciso intervenção escolar, bem como apoio da família ao aluno que foi vítima, um trabalho que merece por vezes acompanhamento de profissionais da área da psicologia, pois pode ter interferência na vida social, afetiva e no psicológico do aluno que sofreu ao bullying, pois geralmente eles são alvos por apresentar-se frágil e não ter reação. "Em alguns casos extremos, o bullying chega a afetar o estado emocional do jovem de tal maneira que ele opte por soluções trágicas, como o suicídio" (TOSITTO, 2016, p. 2).

Para tanto, se faz preciso destacar ainda que $25 \%$ dos alunos, afirmaram que ainda existe alguns atos de violência no ambiente escolar. Dos participantes, $45 \%$ afirmaram que já sofreram alguma violência, onde a verbal foi a de mais destaque, alcançando um percentual de $50 \%$.

Gráfico 4: Tipos de violência sofrida na escola

\section{TIPO DE VIOLÊNCIA SOFRIDA NA ESCOLA}

-VIOLÊNCIA VERBAL $\quad$ VIOLÊNCIA VERBAL E FÍSICA $\quad$ VIOLÊNCIA FÍSICA

$50 \%$

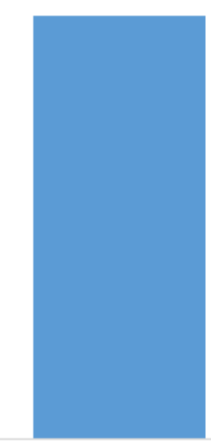

$35 \%$

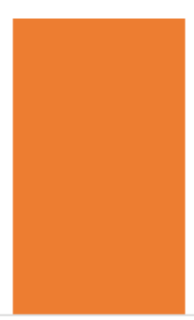

$25 \%$

VIOLÊNCIA VERBAL

VIOLÊNCIA VERBAL E FÍSICA

VIOLÊNCIA FÍSICA

Fonte: Obtidas na pesquisa, 2019. 
Diante do projeto realizado pela escola e a metodologia utilizada os alunos acharam de suma importância, $80 \%$ diz ter feito sim, diferença para os alunos na escola. Destacando como positiva os seguintes pontos:

- $85 \%$ diz ter melhorado a relação social dos alunos na escola.

- $60 \%$ menos discussão,

- $55 \%$ destacou a possibilidade de diálogo,

- $40 \%$ também classificou a união entre alunos como ponto positivo.

Gráfico 5: Melhorias no ambiente da escola

\section{MELHORIAS NO AMBIENTE ESCOLAR}

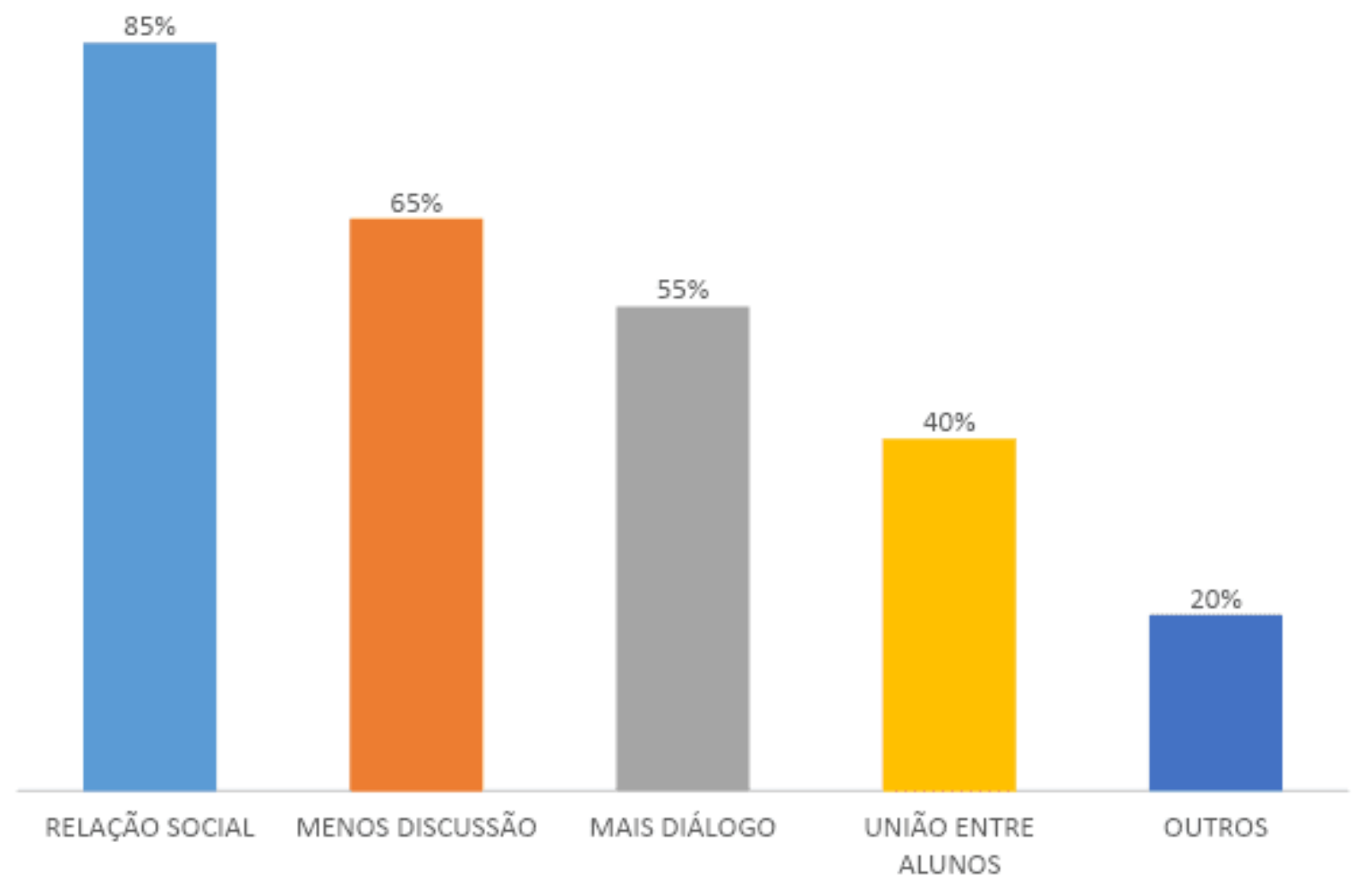

Fonte: Obtidas na pesquisa, 2019.

A importância do projeto deu-se sobre esta nova relação entre os alunos, lógico que ainda há alguns problemas que são supridos no cotidiano, contudo, a objetividade do projeto estar assegurado no seu alcance, nesta abertura de transparecer dos seus 
alunos, em poder dialogar mais, sendo esta uma das característica da Comunicação Não Violenta. É essencial aprender uma linguagem que nos permita construir uma relação de confiança com o próximo. Uma linguagem que aumente a disposição de cooperar e apoiar um ao outro" (FRANK, OLIVEIRA e MARINI, 2013, p. 4).

Entre as ações realizadas na escola os alunos foram incitados a destacar duas que mais gostaram em sua efetividade: $100 \%$ dos alunos destacaram a ação solidária como a atividade que mais gostou e teve efetividade na participação dos alunos. Isto significa que a escola deveria envolver mais ações assim com seus alunos, pois, estas ações agem diretamente na formação do aluno em poder olhar mais para o próximo e sentir-se útil.

E em segundo lugar ficou a "sala do ouvir" com a preferência de $80 \%$ dos alunos, onde eles marcavam para dialogar com a psicóloga no dia agendado para atendimento aos alunos.

Gráfico 6: Atividades do Projeto CNV que tiveram maior significado para os alunos

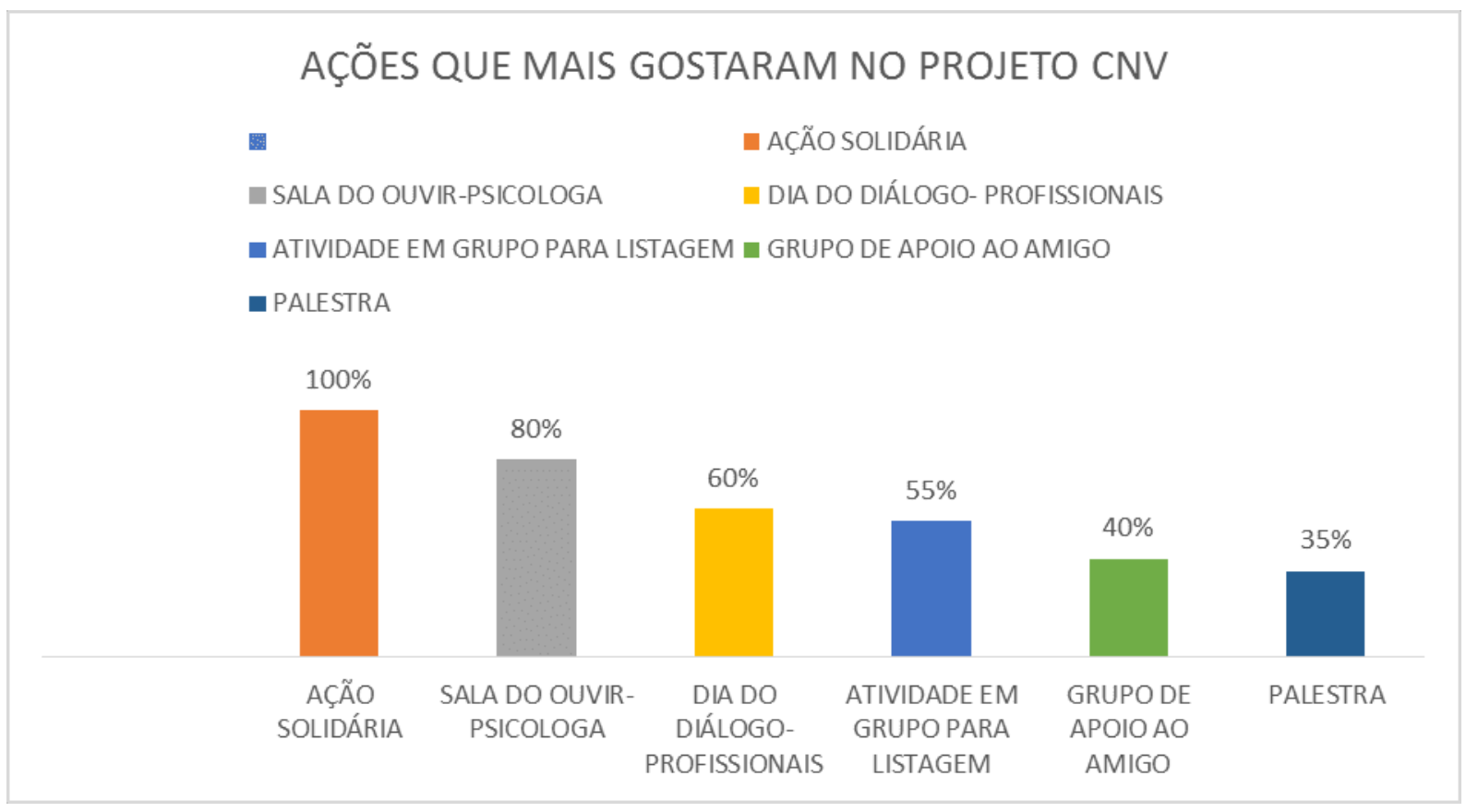

Fonte: Obtidas na pesquisa, 2019. 
É importante refletir aqui sobre como este resultado remete sobre o que Rosemberg destaca na prática da CNV, "o ouvir o outro", "o se colocar no lugar do outro", o de falar o que incomoda a si", são estas características de ações que efetivam a prática do CNV. Ou seja, eles na verdade expuseram a satisfação em libertaram mesmo por instantes dos

[...] comportamentos comuns que nos impedem de estar presentes 0 bastante para nos conectarmos aos outros com empatia [...] aconselhar; competir pelo sofrimento, educar, consolar, contar uma história, encerrar o assunto; solidarizar-se; interrogar; explicar-se e corrigir (ROSENBERG, 2006, p. 135)

Para os alunos a ação solidária significou que eles se identificaram na importância de ajudar o outro que necessita de apoio, ou seja, seja da necessidade material, do conforto, do ouvir, estas significam que eles se importam com o bem estar do outro.

E sobre a oportunidade de agendar um momento de diálogo com a psicóloga, para eles conversarem de como se sentem, isto é, um despojar-se do que mais os incomodava. Assim, a CNV consegue possibilitar no indivíduo a capacidade de expor o que the arrenega-se, de modo a não explicitar o erro do outro, mas, da sua capacidade de expressar o que espera do outro como fator positivo para a relação.

Dar-se no modo de como posso enxergar a situação e reverter a mesma sem causar transtorno à relação, mas, ao mesmo tempo fortalecendo a empatia entre ambos. Onde não se aponta de forma negativa a ação do outro, mas, evidencia ações que o mesmo poderia praticar e não percebeu sua capacidade.

Ou simplesmente pelo fato de que "nós" como indivíduo interpretamos negativamente a ação do outro, ou ainda, porque não soubemos expressar melhor nossa necessidade. "Além de utilizarmos uma linguagem positiva, devemos evitar frases abstratas ou ambíguas e formular nossas solicitações na forma de ações concretas que os outros possam realizar" (ROSENBERG, 2006, p. 106), ou seja, se não soubemos como lidar na comunicação sobre nossas necessidades, facilitamos uma má interpretação. 
Ao questionar os alunos se eles acreditam na efetividade da comunicação não violenta, $70 \%$ disseram que sim, 30\% afirmaram que não. Verifica-se neste resultado, que a maioria dos alunos compreenderam que a Comunicação Não Violenta é uma ação recíproca, contudo, se faz preciso que primeira o indivíduo busque sua prática, ou seja, sua compreensão é interna, não externa. Se faz necessário que se inicie a prática para que o outro reaja positivamente.

\section{CONCLUSÃO}

A Comunicação Não Violenta, discutida neste artigo teve seu foco a partir da experiência vivenciada pelos alunos da Escola E.M.A.P, do qual realizou o projeto Comunicação Não Violenta" no interior do RN, teve sua problemática a busca da resposta da influência exercida nos alunos e se esta causou mudança na relação e na comunicação entre os alunos efetivamente.

Para tanto, se fez necessário uma discussão breve do conceito sobre CNV linha de pesquisa de estudo de Rosenberg, idealizador da temática, como também de outros artigos desenvolvidos a partir de estudos. Na objetividade de analisar os reflexos pós projeto nos alunos, a pesquisa centrou os resultados na visão dos próprios alunos, verificando que dos que se dispuseram a participar da pesquisa, que a escola em seu objetivo de alcançar mudanças na relação e comportamento dos alunos ao ressaltarem a temática sobre CNV, conseguiu influir na mudança de alguns dos seus alunos.

Os participantes revelam que o trabalho desenvolvido foi de suma importância para potencializar uma relação mais afetuosa, conciliadora entre os alunos, contribuindo assim para uma relação mútua, aberta e com olhar mais voltado para a satisfação de suas necessidades individuais, mas, ao mesmo tempo ouvindo o outro. Apresentando sua maneira de sentir com relação ao comportamento do outro em uma posição positiva, não agressiva, não violenta.

A linguagem quando usada positivamente tende a ter respostas mais satisfatórias quando proferidas com autoridade, agressividade, esta maneira de apresentar aos 
alunos a necessidade do diálogo, de se colocar no lugar do outro, de expressar o que sente, aos olhos destes participantes foi fundamental para a harmonia da escola, a relação positiva entre os mesmos.

É fato que há muito ainda o que melhorar, mas, não há dúvidas de que a escola iniciou um processo muito positivo com seus alunos, não se pode parar e pensar que tudo foi restabelecido, há considerações a serem supridas, mas, com o hábito da prática, da formação e dos acompanhamentos contínuos, a escola tende a construir entre seus alunos, mudanças não tão somente internas, mas, mudanças que farão diferença no meio externo em que seus alunos estão inseridos.

\section{REFERÊNCIAS}

FRANKE, Ana Paula. OLIVEIRA, Eder Conrado de. MARINE, Mariangela Comunicação Não Violenta. SIPAT, 2013. 21p.

PELIZZOLI, M.L. (org.) Diálogo, mediação e cultura de paz. Recife: Ed. da UFPE, 2012.

PRODANOV, Cleber Cristiano. FREITAS, Ernani Cesar de. Metodologia do trabalho científico [recurso eletrônico]: métodos e técnicas da pesquisa e do trabalho acadêmico / 2. ed. - Novo Hamburgo: Feevale, 2013.

ROSEMBERG, Marshall B. Comunicação não-violenta: técnicas para aprimorar relacionamentos pessoais e profissionais I Marshall B. Rosenberg; [tradução Mário Vilela]. - São Paulo: Ágora, 2006.

TOSITTO, Ana Maria Logatti. BULLYING ESCOLAR NA ADOLESCÊNCIA. 2018.

Enviado: Agosto, 2019.

Aprovado: Novembro, 2019. 